\title{
Philosophical and Ethical Perspectives on How We Could Know Recovery from Schizophrenia and Their Impact on Knowledge Development
}

\author{
Minjeong Kim \\ School of Nursing, San Diego State University, San Diego, USA \\ Email: minjeong.kim2@gmail.com
}

How to cite this paper: Kim, M. (2017) Philosophical and Ethical Perspectives on How We Could Know Recovery from Schizophrenia and Their Impact on Knowledge Development. Open Journal of Psychiatry, 7, 31-39.

http://dx.doi.org/10.4236/ojpsych.2017.71003

Received: September 16, 2016

Accepted: December 12, 2016

Published: December 15, 2016

Copyright $\odot 2017$ by author and Scientific Research Publishing Inc. This work is licensed under the Creative Commons Attribution International License (CC BY 4.0).

http://creativecommons.org/licenses/by/4.0/

\begin{abstract}
This paper discussed various philosophical and ethical perspectives on how to know recovery from schizophrenia. According to the empirical approach, recovery can be measured by objective and standardized tools which evaluate the severity of psychiatric symptoms or levels of social and vocational functioning. These measurements have minimum scores or sets of criteria of what recovery looks like, so this approach may be useful to evaluate patient's treatment outcomes by healthcare providers. On the contrary, phenomenological approach stands qualitative research methods to understand an individual's subjective, lived, or unique experiences while he or she lives with schizophrenia. Historical perspective holds that a point of view on recovery has been changed from negative to positive as our social perspectives for schizophrenia changes. Feminist perspective suggests that recovery can be understood by exploring female's subjective experiences like successful marriage life or having responsibility for children. Ethical perspectives regarding the meaning of recovery were also addressed. Each philosophical and ethical perspective guides different research methodology and methods. Therefore, to employ appropriate methodology and methods, understanding philosophical and ethical backgrounds would be important.
\end{abstract}

\section{Keywords}

Schizophrenia, Recovery, Philosophy, Ethics

\section{Introduction}

Schizophrenia is one of the most serious and chronic mental disorders characterized by positive and negative symptoms, which leads to a functional deterioration. Lifetime prevalence of schizophrenia is about $1 \%$ of the general population of the world [1]. Up until 1970s, the course of and recovery from schizophrenia had been regarded as pessimistic. However, due to a wide use of antipsychotic drugs, deinstitutionalization of 
people with schizophrenia and the concept of psychiatric rehabilitation arose. Community-based mental health systems began to provide people with schizophrenia with various programs to manage their psychiatric symptoms and to develop their social and vocational skills [2].

This changed view about the course of schizophrenia can be accounted by not only the introduction of antipsychotic drugs, but many other factors such as a landmark study on the prognosis of schizophrenia conducted by Harding, Brooks, Ashikaga, Strauss, \& Breier [3], studies on a new definition of recovery from severe mental disorders by Anthony [2] and Jacobson \& Greenly [4], and numerous qualitative studies about lived experience of people with schizophrenia [5]-[12].

Many studies have been conducted to understand what recovery from mental disorders means and to measure its features or characteristics. There are two different conceptualizations of recovery, so called, scientific vs. consumer perspectives, outsider vs. insider views, and outcome-oriented vs. process-oriented views [13] [14] [15]. At a glance, scientist, outsider, and outcome-oriented perspectives look different, however, all of these have a similar conceptualization about recovery because they are driven from the same philosophical background, empiricism. Empirical perspective focuses on external reality and observable things, meaning that which is measurable. On the other hand, consumer, insider, and process-oriented perspectives are based on phenomenology which underscores behind the surface phenomena and data, and lived experience of people [16] [17].

Therefore, this paper: 1) reviewed philosophical and ethical backgrounds on how we could know a person with schizophrenia has recovered or is recovering, and 2) discussed how these perspectives could affect the knowledge development on recovery from schizophrenia.

\section{Philosophical Perspectives on Recovery from Schizophrenia}

\subsection{Empirical Perspective}

Empiricism holds that knowledge is acquired by experience. Experience is defined as sensory data or information particularly about the objects of the world derived by using the senses. Empiricists focus on observable which is measurable by sense. In order to develop knowledge, empiricists must gain clear and accurate representations of the world by focusing on the physical world. This approach sees science as an act of discovery, rather than of invention [16] [18] [19]. This philosophical tradition has influenced modern science and traditional research methods. Specifically, sensory data including visual cues and physiologic measures have an important role in developing health science. Moreover, research methods using observational tools to collect data, have been regarded as one of the strong traditional research methods in health [16].

From this empirical approach, recovery from schizophrenia can be understood in terms of symptom relief or functional outcomes on an individual level. People with schizophrenia have positive and negative symptoms. These symptoms can be measured using observational tools by health care providers. Liberman, Kopelowicz, Ventura, \& Gutkind [20] identified four operational criteria of recovery: symptom remission, vocational functioning, independent living, and peer relationships. Symptom remission is 
measured by the Brief Psychotic Rating Scale (BPRS) score of four or less on the key psychotic symptoms. Other criteria are measured by at least half time of work or school, independent management of funds and medication, and once weekly socialization of peers for at least two years. Whitehorn, Brown, Richard, Rui, \& Kopala [21] measured recovery using the Positive and Negative Syndrome Scale (PANSS) score of four or less on psychotic symptoms, the Global Assessment of Function (GAF) score of more than 50, and the Social and Occupational Functional Assessment (SOFA) score of more than 60. Andreasen et al. [22] proposed criteria for remission in schizophrenia: mild or less delusions, hallucinations, thought disorder, bizarre behavior, affective flattening, apathy, anhedonia, and alogia for at least six months.

There is no doubt that empiricism has played a significant role in knowing the meaning of recovery of persons with schizophrenia. Empiricism emphasizes the development of a general theory or rule. This theory or rule can help us with manipulation and control over our lives looking at recovery from schizophrenia. Through the empirical perspective, the symptom remission and vocational and social functional improvements can be utilized to advance the science of knowledge about recovery. In terms of the perspective of health care providers, the empirical approach seems useful for evaluating whether or not a person with schizophrenia has recovered one's function. This judgment requires objective descriptions including objective data. However, this empirical approach has several limitations. It views recovery as objective and observable. It does not consider the subjective and personal experiences of humans. Moreover, this approach views recovery on an individual level, not on a family level. Therefore, the understanding of recovery can be expanded by recognizing the individual's subjective and social aspects. The examination of different philosophical tradition such as phenomenology is needed to understand the meaning of recovery better.

\subsection{Hermeneutics and Phenomenological Perspective}

Hermeneutics is a process of interpretation, and is to understand fully something behind the phenomena, not just fragments [16]. Hermeneutics, as a way of studying the phenomenological realms, has been used to understand everyday practices, meanings, and knowledge [17]. The phenomenological approach sees a person the notion of "thrownness" and "being-in-the-world" [23]. Therefore, knowledge could be accumulated through understanding the meaning within the context and condition that an individual experiences. Through the hermeneutic circle, meaning the process from pre-understanding to understanding to pre-understanding again, understanding proceeds [16].

From phenomenological perspective, recovery is understood in terms of the subjective and unique experience of an individual or family. Anthony [2] defined recovery from mental disorders as a way of living that might involve the development of new meaning and purpose in one's life as the individual grows beyond the catastrophic effects of mental illness. He viewed recovery as a "deeply personal, unique process of changing one's attitude, values, feelings, goals, skills, and/or roles.” More recently, Jacobson and Greenley [4] addressed a multi-dimensional concept of recovery consisting of internal conditions such as hope, healing, empowerment, and connection, as well as external conditions such as human rights, a positive culture of healing, and recovery- 
oriented services. Noordsy et al. [24] saw recovery as hope, taking personal responsibility, and getting on with life beyond illness. Resnick, Fontana, Lehman, \& Rosenheck [25] developed an empirical conceptualization of recovery: empowerment, hope and optimism, knowledge about mental illness and services, and life satisfaction.

From numerous qualitative studies on what recovery looks like, several common themes were explored: overcoming stuckness, redefining their identity, self-empowerment, hope, understanding mental illness and preventing relapse, returning to basic functioning, improving quality of life, reintegration with context, and finding acceptance and ways to advocate [5] [6] [8] [10] [12]. In addition, a few tools were developed to measure subjective aspects of recovery. One is the recovery assessment scale (RAS), which measures personal confidence and hope, willingness to ask for help, reliance on others, no domination by symptoms, and goal and success orientation [26]. Another is the mental health recovery measure (MHRM), which identifies a three-phase model of recovery: 1) overcoming stuckness; 2) discovering and fostering self-empowerment, learning and self-redefinition, and return to basic functioning; and 3) striving to attain overall wellbeing and striving to reach new potentials [7].

Phenomenological approach generates forms of explanation and predictions that offer understanding and choice. This perspective allows us to broaden our views and to provide the opportunity to get to something behind objective and measurable recovery [17]. This approach suggests that people have different experiences and perspectives in the process of recovery and enables a deeper and more thoughtful understanding of human experience [16]. Through the phenomenological perspective, human elements such as social relationships with family and friends, health professionals, and society can be understood more deeply. These cannot be understood by the accurate observation of the observables of empiricism. Patients and their families live together with schizophrenia for their lifetimes. Symptoms of schizophrenia can be improved or aggravated depending on their medication adherence, general condition, or use of rehabilitation. However, patients think that they are still in the process of recovery. This means that other obstacles influencing their recovery such as lack of medication adherence during certain periods of time cannot be regarded as non-recovery. Many of them are looking for hope that they will recover. Therefore, to understand this meaning of recovery prevailing in the patients and their family members, the phenomenological perspective seems useful.

However, this phenomenological approach has its limitations. With this approach, living with schizophrenia includes diverse and multiple aspects of the daily lives of patients and families. This makes it hard to determine what recovery is and how it can be explained by a generalized rule. This indicates that the recovery from mental illness cannot be understood only by empirical or phenomenological perspectives. Although we can understand the subjective aspects of recovery better using the RAS or the MHRM, these tools are still problematic in terms of inconsistent domains and variables.

\subsection{Historicism}

Historicism holds an adequate understanding of the nature and value of anything which requires consideration of its place and role within a process of historical devel- 
opment. Scientific development must be examined in regard to the context in which they occurred. In contrast with logical positivism, historicism takes the position that science is to be understood and evaluated by the process, not by a product. This approach provides both a methodological principle regarding how to understand situations and a philosophy about how situation came to exist [16]. According to Kuhn, science is gained not only by collecting empirical data, but also involves the human element. He also emphasizes the creativity and innovation within the imposed by the paradigm, which are important to the area of health because it has attributes of diverse and dynamic nature of human beings and health situations [16].

With a historical approach, the recovery from schizophrenia can be understood in terms of the change in social perspectives for the disease, resulting in the change of health situations. The point of view for recovery from schizophrenia in the past was not the same as that of the present. For example, just a few decades ago, schizophrenia was perceived as being crazy or captured with an evil spirit. Thus, schizophrenia was recognized as being not cured or recovered. Human rights of the patients were also not respected. However, with the liberation movement by patients with mental disorders, perspectives on the recovery has been changing from the negative to the positive belief that schizophrenia can be recovered and human rights for the patients should be respected like that of lay people. Therefore, self-help, empowerment, and advocacy of patients with mental disorders have been developed [13] [27]. With the understanding of historical context about the recovery, we understand the change in meaning of recovery and schizophrenia more deeply. This historical view had influenced the development of health science by increasing the understanding of social context. Through the historical development, the meaning of recovery will have the room to be changed.

\subsection{Feminist Perspective}

Feminist perspective's key tenets are that the major source of knowledge can be drawn from contextually-oriented women's subjective experiences [28]. This approach holds that many studies conducted up-until now were affected by masculine bias in terms of its concepts, theories, methods, and interpretations of findings of studies, therefore, the results of studies were standardized for male [29]. The patriarchal view can bear problems with misapplication because women's unique activities or experiences are not considered in this view [16].

In order to discover what recovery from schizophrenia means with feministic view, women's subjective experiences about recovery from schizophrenia should be asked and contexts of the phenomena should be considered across the study. Research questions should be for women. Interpretations of findings should be validated with study participants [28]. Through feministic view, health science about women's experiences of recovery from schizophrenia can be developed, including successful marriage life, having responsibility for children, caring for others, and so on.

\section{Ethical Perspectives on Recovery from Schizophrenia}

\subsection{Utilitarianism}

As one of the consequentialism, utilitarianism determines whether the action is right or 
wrong according to its consequences, rather than reason or process. This approach focuses on the value of well-being, such as happiness, freedom, and health, strictly according to the principle of utility. This means that we should produce the maximum value for the greatest number. This view is based on the idea that individuals have an equal weight for the interests [30]. From this utilitarian approach, right thing is to produce maximum health for the greatest number. Here, in terms of recovery from schizophrenia, one might ask, "If much more resources are distributed to persons with schizophrenia to improve their health, rather than persons without disease, is that for the greatest number?" In order to answer to this, productivity, one of the important factors in determining what the good consequence is, should be considered. During the acute stage of schizophrenia, a person cannot produce desirable goods for the society. At this point, he or she is often regarded as useless one from the point of utilitarianism. However, through continuous acute and rehabilitation treatment, the patient can develop social or vocational skills which are necessary to become more productive person for his or her society. Therefore, to improve health of persons with schizophrenia is regarded as the good consequence for the greatest number of individuals only if the person has productivity.

\subsection{Kantianism}

Kantianism poses the opposite perspective from utilitarianism. Action can be judged by reasons, so called rational powers, rather than the consequences of actions. It means that the moral reason can justify one's action, which is provided by the objective rule. Everyone in a similar situation must follow the moral rule. Treating person with respect and moral dignity is another important tenet of Kantianism. Therefore, we always should treat person as an end, not as a means [30]. According to Kant, actions to improve or produce health of persons with schizophrenia should be considered as right if they are morally acceptable and based on moral rules. Treating or continuing treatment of disease, providing rehabilitation and community-based cares, improving therapeutic environment, and doing an advocate role for patients and family members are examples of moral actions. Recovery matter cannot be viewed as a result such as the productivity that a patient shows. In addition, when we always respect patients as human being in a positive culture of healing regardless of their status of disease, the patients are to recover.

\subsection{Communitarianism}

Communitarianism holds that a commitment to a community which shares communal values, social goals, and cooperative virtues, is elementary in ethnics. This approach suggests that an individual is influenced by one's society. It is only social roles that can determine what people ought to do, not the individual's value [30]. From this communitarian approach, how we could know a patient has recovered or is recovering from schizophrenia can be determined by the shared point of view of the community. Members of the community share similar idea with each other. This idea is deeply rooted in communal tradition and practices. A particular perspective a member has in particular community has its ethical power. Consequently, understanding a particular feature of 
recovery requires an understanding of the community's history and social welfare.

\subsection{Rights Theory}

Right theory underscores liberty, expression, and protection of life against oppression and unequal treatment raised by communitarianism or utilitarianism. These rights are the basis of moral judgment. From the rights, rules and obligations are derived [30]. From this approach, understanding the recovery from schizophrenia is based on human right. We often see injustice and inhumane treatment to persons with schizophrenia. There still exists inequality in employment due to their lower job skills, lower productivity, and stigma. In this sense, recovery means that persons with schizophrenia are to be free from these unequal treatments and injustice and fight for their rights.

\section{Conclusions}

As presented, what a person recovering from schizophrenia looks like is somewhat different. Some people see recovery as relieved positive and negative symptoms or functional improvement of a patient with schizophrenia, however, others regard the phenomena of recovery as having hope and responsibility, enhancing quality of life, and healing process. Although women's experiences have been rarely seen in these concepts, it is evident that these are major points when considering definitions of recovery from schizophrenia.

Employing different methodology in studies usually produces different methods and results. Methodology guides research studies at a theory level, and method is a technical way to gather data [28]. Methodology can be affected by the way a researcher looks at the phenomena of interest, which means philosophical perspective. In this paper, four different philosophical perspectives were presented in relation to how to know recovery from schizophrenia. Traditionally, empiricism has affected knowledge development by accumulating observable or measurable data. Up-until know, this way of knowing is most commonly used in health-related research studies as a quantitative research method. More recently, phenomenological approach was introduced and used to explore an individual's subjective experience, which cannot be captured under empiricism. A qualitative research method was driven by phenomenology. Although both historicism and feminist perspective are based on social contexts, they are still minor perspectives, and feminist perspectives believe that female's experience is a legitimate source of knowledge.

Ethical perspectives also can influence methodology in research studies. At a glance, ethical perspectives are regarded as a guiding principle to decide whether what a person or a group did is right or wrong. When you look inside ethical perspectives, such as utilitarianism vs. Kantianism, and communitarianism vs. rights theory, some methodological thoughts that ethical perspectives can guide studies can be raised. Common interest of both utilitarianism and Kantianism is about result vs. motivation of a person's behaviors. This could be applied to whether recovery from schizophrenia can be known as a result or a process or motivation of the person. A shared or an individual's point of view is the main interest of communitarianism and rights theory. Therefore, when recruiting study participants, it is important to decide who the informant should be, who 
can tell the phenomena of recovery.

\section{References}

[1] Preti, A. and Miotto, P. (2005) Genetics, Perinatal Insult and Schizophrenia: The Mechanism Underlying an Increased Prevalence of Perinatal Complications among Individuals with a Diagnosis of Schizophrenia? Current Psychiatry Reviews, 1, 139-150. https://doi.org/10.2174/1573400054065596

[2] Anthony, W.A. (1993) Recovery from Mental Illness: The Guiding Vision of the Mental Health Service System in the 1990s. Psychosocial Rehabilitation Journal, 16, 11-23. https://doi.org/10.1037/h0095655

[3] Harding, C.M., et al. (1987) The Vermont Longitudinal Study of Persons with Severe Mental Illness: II. Long-Term Outcome of Subjects Who Retrospectively Met DSM-III Criteria for Schizophrenia. The American Journal of Psychiatry, 144, 727-735. https://doi.org/10.1176/ajp.144.6.727

[4] Jacobson, N. and Greenley, D. (2001) What Is Recovery? A Conceptual Model and Explication. Psychiatric Services, 52, 482-485. https://doi.org/10.1176/appi.ps.52.4.482

[5] Young, S.L. and Ensing, D.S. (1999) Exploring Recovery from the Perspective of People with Psychiatric Disabilities. Psychiatric Rehabilitation Journal, 22, 219-231. https://doi.org/10.1037/h0095240

[6] Bradshaw, W., Armour, M.P. and Roseborough, D. (2007) Finding a Place in the World: The Experience of Recovery from Severe Mental Illness. Qualitative Social Work, 6, 27-47. https://doi.org/10.1177/1473325007074164

[7] Andresen, R., Caputi, P. and Oades, L. (2006) Stages of Recovery Instrument: Development of a Measure of Recovery from Serious Mental Illness. The Australian and New Zealand Journal of Psychiatry, 40, 972-980. https://doi.org/10.1080/j.1440-1614.2006.01921.x

[8] Jensen, L.W. and Wadkins, T.A. (2007) Mental Health Success Stories: Finding Paths to Recovery. Issues in Mental Health Nursing, 28, 325-340. https://doi.org/10.1080/01612840701244086

[9] Noh, C., Choe, K. and Yang, B. (2008) Hope from the Perspective of People with Schizophrenia (Korea). Archives of Psychiatric Nursing, 22, 69-77. https://doi.org/10.1016/j.apnu.2007.10.002

[10] Noiseux, S. and Ricard, N. (2008) Recovery as Perceived by People with Schizophrenia, Family Members and Health Professionals: A Grounded Theory. International Journal of Nursing Studies, 45, 1148-1162. https://doi.org/10.1016/j.ijnurstu.2007.07.008

[11] Roman, M.W. (2006) The Process of Recovery: A Tale of Two Men. Issues in Mental Health Nursing, 27, 537-557. https://doi.org/10.1080/01612840600600016

[12] Ochocka, J., Nelson, G. and Janzen, R. (2005) Moving Forward: Negotiating Self and External Circumstances in Recovery. Psychiatric Rehabilitation Journal, 28, 315-322. https://doi.org/10.2975/28.2005.315.322

[13] Brown, C., Rempfer, M. and Hamera, E. (2008) Correlates of Insider and Outsider Conceptualizations of Recovery. Psychiatric Rehabilitation Journal, 32, 23-31. https://doi.org/10.2975/32.1.2008.23.31

[14] Silverstein, S.M. and Bellack, A.S. (2008) A Scientific Agenda for the Concept of Recovery as It Applies to Schizophrenia. Clinical Psychology Review, 28, 1108-1124. https://doi.org/10.1016/j.cpr.2008.03.004

[15] Bellack, A.S. (2006) Scientific and Consumer Models of Recovery in Schizophrenia: Concordance, Contrasts, and Implications. Schizophrenia Bulletin, 32, 432-442. https://doi.org/10.1093/schbul/sbj044 
[16] Rodgers, B.L. (2005) Developing Nursing Knowledge: Philosophical Traditions and Influences. Lippincott Williams \& Wilkins, Philadelphia.

[17] Benner, P. (1985) Quality of Life: A Phenomenological Perspective on Explanation, Prediction, and Understanding in Nursing Science. Advances in Nursing Science, 8, 1-14. https://doi.org/10.1097/00012272-198510000-00004

[18] Geanellos, R. (1997) Nursing Knowledge Development: Where to from Here? Collegian, 4, 13-21. https://doi.org/10.1016/S1322-7696(08)60201-2

[19] Packard, S.A. and Polifroni, E.C. (1992) The Nature of Scientific Truth. Nursing Science Quarterly, 5, 158-163. https://doi.org/10.1177/089431849200500407

[20] Liberman, R.P., Kopelowicz, A., Ventura, J. and Gutkind, D. (2002) Operational Criteria and Factors Related to Recovery from Schizophrenia. International Review of Psychiatry, 14, 256-272. https://doi.org/10.1080/0954026021000016905

[21] Whitehorn, D., Brown, J., Richard, J., Rui, Q. and Kopala, L. (2002) Multiple Dimensions of Recovery in Early Psychosis. International Review of Psychiatry, 14, 273-283. https://doi.org/10.1080/0954026021000016914

[22] Andreasen, N.C., et al. (2005) Remission in Schizophrenia: Proposed Criteria and Rationale for Consensus. The American Journal of Psychiatry, 162, 441-449. https://doi.org/10.1176/appi.ajp.162.3.441

[23] Leonard, V.W. (1989) A Heideggerian Phenomenologic Perspective on the Concept of the Person. Advances in Nursing Science, 11, 40-55. https://doi.org/10.1097/00012272-198907000-00008

[24] Noordsy, D., Torrey, W., Mueser, K., Mead, S., O’Keefe, C. and Fox, L. (2002) Recovery from Severe Mental Illness: An Interpersonal and Functional Outcome Definition. International Review of Psychiatry, 14, 318-326. https://doi.org/10.1080/0954026021000016969

[25] Resnick, S.G., Fontana, A., Lehman, A.F. and Rosenheck, R.A. (2005) An Empirical Conceptualization of the Recovery Orientation. Schizophrenia Research, 75, 119-128. https://doi.org/10.1016/j.schres.2004.05.009

[26] Corrigan, P.W., et al. (2004) Examining the Factor Structure of the Recovery Assessment Scale. Schizophrenia Bulletin, 30, 1035-1041. https://doi.org/10.1093/oxfordjournals.schbul.a007118

[27] Chamberlain, J. (1990) The Ex-Patient's Movement: Where We've Been and Where We're Going. Journal of Mind and Behavior, 11, 323-336.

[28] Campbell, J.C. and Bunting, S. (1991) Voices and Paradigms: Perspectives on Critical and Feminist Theory in Nursing. Advances in Nursing Science, 13, 1-15. https://doi.org/10.1097/00012272-199103000-00004

[29] Harding, S. (1986) The Instability of the Analytical Categories of Feminist Theory. Signs, 11, 645-664. https://doi.org/10.1086/494270

[30] Beauchamp, T.L. and Childress, J.F. (2009) Principles of Biomedical Ethics. 6th Edition, Oxford University Press, New York. 
Submit or recommend next manuscript to SCIRP and we will provide best service for you:

Accepting pre-submission inquiries through Email, Facebook, LinkedIn, Twitter, etc. A wide selection of journals (inclusive of 9 subjects, more than 200 journals) Providing 24-hour high-quality service

User-friendly online submission system

Fair and swift peer-review system

Efficient typesetting and proofreading procedure

Display of the result of downloads and visits, as well as the number of cited articles Maximum dissemination of your research work

Submit your manuscript at: http://papersubmission.scirp.org/

Or contact ojpsych@scirp.org 